BULLETIN OF THE GEOLOGICAL SOCIETY OF AMEAICA

VOL. 23, PP. 93-124

MARCH 21, 1912

\title{
RELATION OF GEOGRAPHY TO GEOLOGY ${ }^{1}$
}

\author{
ANNUAL ADDRESS OF THE PRESIDENT, W. M. DAVIS
}

(Read before the Society December 29, 1911)

\begin{abstract}
CONTENTS
Page

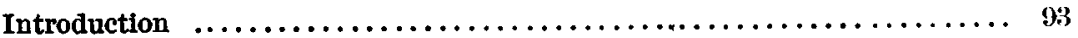

Part I. The use of explanatory geological matter as a means to a geo-

graphical end $\ldots \ldots \ldots \ldots \ldots \ldots \ldots \ldots \ldots \ldots \ldots \ldots \ldots \ldots \ldots \ldots, 94$

An explanatory description of the Colorado Front Range......... 94

Geological elements in geographical descriptions.............. 95

Classification of the sciences......................... 97

Geographical pertinence of explanatory phrases.............. 99

The expansion of condensed phrases into their full meaning....... 100

Implicit explanations in geographical terms................ 102

Technical explanatory treatment of land forms............. 103

Part II. The necessity of explanatory treatment in morlern geography... 104

Empirical and explanatory geographical descriptions............ 104

Advantages of explanatory treatment.................... 105

Grounds of choice between empirical and explanatory methods...... 106

Trend of modern geography toward explanatory treatment....... 108

Limitation of geological elements in geographical descriptions...... 109

The geological nature of certain geographical studies........... 111

Part III. The diminution of apparently geological matter in geographical

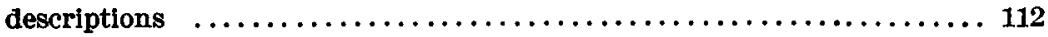

The advantage of terms over phrases..................... 112

An experiment in the invention of a term.................. 115

Morvans of dffferent kinds.......................... 117

The Colorado Front Range is a morvan.................. 118

Concealed geological meaning in various geographical terms...... 119

Part IV. The relation of geography to geology $\ldots \ldots \ldots \ldots \ldots \ldots \ldots \ldots 120$

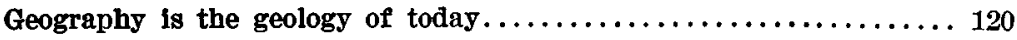

Reasons for maintaining each as a separate science........... 122
\end{abstract}

\section{INTRODUCTION}

Nearly a year ago I had occasion to speak at a meeting of the Geological Society of Washington on the subject "Geographical Descriptions in Geological Publications," with special reference to an explanatory

1 Read before the Society December 29, 1911.

Manuscript received by the Secretary of the Society January 18, 1912. 
method of describing the forms of the lands. In illustration of the principles that seemed to me most important I introduced a brief and technical geographical description of the land forms seen in the Front Range. of the Rocky Mountains in central Colorado during an excursion in the summer of 1910, regarding which a fuller account is about to be published in the Annals of the Association of American Geographers; yet at the close of the meeting the feeling prevalent among some of the geologists present seemed to be that my description did not belong under geography, but under geology. The description had seemed to me to belong under geography, and to be indeed as good a piece of geography, in so far as land forms enter into geography, as I could make, because its object was the description of the existing landscape. Yet, in the opinion of geologically competent listeners, what I had said was not geography; it was geology. Evidently, then, the relations of these two sciences are not fully agreed on. I therefore propose to devote this address to the "Relation of Geography to Geology," with special relation to the forms of the lands, in the hope of showing at least my own grounds for regarding as geography what other members of our Society may consider to be essentially geology.

The address is divided into four parts. The first discusses the use of explanatory geological matter as a means to a geographical end; the second shows the necessity of explanatory treatment in modern geography; the third proposes a device by which the presence of geological matter in geographical descriptions is made inconspicuous, and the fourth turns more particularly to the general topic of the address, the relation of geography to geology.

\section{Part I. The Use of explanatory geological Matter as a Means TO A GEOGRAPHIOAL END}

\section{AN EXPLANATORY DESCRIPTION OF THE COLORADO FRONT RANGE}

The brief and technical description of the Front Range, the systematic place of which in the two sciences appeared last winter to be in doubt, was, as nearly as I can now reproduce it, as follows:

The Front Range of the Rocky Mountains in central Colorado, northwest of Denver, is a highland of disordered and generally resistant crystalline rocks, which show signs of having been long ago worn down from its initially greater mass to a surface of faint relief, slowly depressed and more or less broadly buried under a heavy cover of sedimentary strata. Then, as the result of a widespread uplift, a part of the compound mass west of a pronounced monoclinal displacement along a north-south line, came to stand above the rest, and thus the highland province of the moun- 
tains was marked off from that of the less uplifted plains on the east. The forms of the highland shows that the whole region advanced far through the cycle of erosion introduced by the monoclinal uplift, so that the resistant underlying crystalline rocks of the mountain area were stripped of their cover and worn down to a gently rolling peneplain, diversified by irregularly scattered monadnocks, rising singly or in groups, with a relief of from 500 to 2,500 feet, while the valleys of the highland show that a renewed uplift gave the whole region a greater altitude than before, with a gentle up-arching along a north-south axis in the mountain area 15 or 20 miles west of the monocline, whereby the peneplain, with its scattered monadnocks, gained the highland altitude of the present Front Range; the crest of the up-arching and the monadnocks that happened to lie near it defining in a general way the crest of the range, which here constitutes the continental divide. The weaker strata of the plains are now again worn down to small relief, but the harder crystalline rocks of the mountainous highland are only submaturely dissected by normal submature or mature valleys, the higher parts of which have recently been strongly glaciated. Thus ends the description.

\section{GEOLOGICAL ELEMENTS IN GEOGRAPHICAL DESCRIPTIONS}

It is quite possible that many hearers now present will regard this description as having at least a highly geological flavor, even if they do not think it pure geology. Let us inquire, therefore, on what elements of the description such an opinion may be based. First, I presume, on the mention of certain kinds of rocks, namely, disordered crystallines and stratified sedimentaries; second, on the mention of the structure given to these rocks by uplift and deformation which took place in past ages; third, on the mention of erosional processes, glacial as well as normal, acting in the past, and of the work that they have accomplished. Let us examine these elements separately in the order just stated, with the object of learning how far their presence determines the geological or the geographical nature of a description that contains them.

If the mention of rock composition determines that a description should belong under geology instead of under geography, then such phrase as the cross-bedded sandstones of the White cliffs in southern Utah, the chalk cliffs of southeastern England, the basaltic columins of the Giants causeway, the dolomite mountains of the $\mathrm{T}$ yrol, the sand dunes of the Sahara, and so on, all belong in geology and not in geography; nevertheless, such descriptions are often, and I think quite properly, found in geographical literature.

Rock attitude as well as rock composition may be mentioned, as in de- 
scriptive phrases like the bench of horizontal sandstone overlying the disordered crystalline rocks which are exposed in the steep-walled gorge at the bottom of the Colorado Canyon, or the long ridges of steeply inclined sandstone strata, which turn in sharp zigzags around the gently pitching anticlines and synclines of the Alleghenies in central Pennsylvania. Such descriptions must be doubly geological if rock attitude as well as rock composition are allowed, mentioned only under geology and never under geography; but they surely deserve a place in geography also, for such descriptions are of great value in describing the visible features of existing landscapes.

If the mention of past processes of deposition, deformation, or erosion withdraws a statement from geography and transfers it to geology, then such phrases as wind-heaped sand dune, wave-built sand reef, wave-cut cliff, river-cut gorge, glacial cirque, tilted fault block, and uplifted peneplain are all geological. Indeed many simple terms, like delta, atoll, volcano, landslide, moraine, peneplain, in which it is tacitly implied that some process has acted through some portion of past time to produce a certain actually visible form, all become geological terms and must no longer be regarded as geographical. All these terms will be lost to geography if the explicit or implicit introduction of past process determines a term to be of geological nature; yet surely they belong in geography, and geography can not let them go. Doubly geological would be such phrases as a dissected volcanic cone; a maturely dissected landslide; an uplifted and slightly dissected delta; a tilted, dissected, and then glaciated peneplain; for these phrases suggest the action of past processes in double, triple, or quadruple succession, and thus imply the division of past time into chapters. Surely it is not to be questioned that such a treatment of existing forms has a highly geological flavor; yet the phrases, nevertheless, are to my reading good geographical phrases, because they so concisely and definitely characterize existing land forms.

If mention of process acting through time be associated with mention of rock composition and attitude, then descriptions thus phrased would be of a still more pronounced geological quality, provided that geological quality is really determined by mere mention of process, composition, and attitude ; witness the following examples: A dissected bench of horizontal sandstones unconformably overlies the ancient peneplain of disordered fundamental crystallines in which the inner gorge of the Colorado Canyon has been eroded, or Snowden is a mass of deformed slates and lavas of subequal resistance, as a whole worn down to subdued form by normal erosive agencies, but possessing great cirques recently excavated in its valley heads by local glaciers. Yet both of these descriptions belong very prop- 
erly, in my opinion, under geography, because they give us good pictures of land forms now existing.

Finally, if in addition to statements concerning the rock structure of the land-mass that is to be worked on, and concerning the erosive agents that do the work, we add some indication of the amount of erosional work that has been done by the working agent, and thus suggest a rather definite measure to the periods of past time that have been involved in the production of existing land forms, then the geological quality of such a description would become all the more pronounced, provided that mention of structure to be worked on, of agencies that have done the work, and of the stage of work reached by the agencies in their work on the structural mass necessarily determine a description to be geological instead of geographical. For example: Southern New England is chiefly composed of disordered and for the most part resistant crystalline rocks, with an irregularly defined north-south trend, which was long ago worn down to a peneplain, save for a few scattered monadnocks of small relief; since then uplifted to its present altitude with a gentle slant to the southeast, and after being for the most part maturely dissected by normal agencies, recently strongly glaciated by an overwhelming ice-sheet and then left in a slightly depressed position, so that the distal parts of its valleys are somewhat drowned. Or, again, central England is occupied by a heavy series of sedimentary strata, slanting gently to the southeast from an irregular and deeply eroded oldland of complicated structure, the sedimentary series including a first or basal member, a third or medial member, and a fifth or uppermost member of relatively weak clays or marly sandstones, and a second and a fourth member of relatively resistant limestone or chalk, the whole region seeming now to be in a well advanced stage of a second cycle of normal erosion, following the old age of a previous cycle, so that it possesses two well defined cuestas determined by the resistant strata, separating an inner, a medial, and an outer lowland eroded on the weak strata, all these features trending northeast-southwest with the strike of the strata and drained for the most part by well adjusted river systems.

\section{OLASAIFICATION OF THE SOIENOES}

Some students of earth science would regard brief descriptive phrases, such as a maturely dissected landslide or an uplifted and slightly dissected delta, as still in good measure geographical because of their simplicity, while they would regard the descriptions of New England and of old England, just quoted, and still more the longer description of the Colorado Front Range, as geological because of their greater quantity of VII-Bors. GmoL. Soc. AM., Voc. 28, 1911 
reference to rock structures and to past processes. But it may be fairly urged in relation to all these examples that the science to which a description belongs can not be determined by the devices that it employs, nor by the simplicity or the detail of the statements that it contains, but by the object in view and by the pertinence of such matters as are stated to the accomplishment of that object. Let me illustrate this principle by analogy.

When a chemist weighs a precipitate, does his work belong under physics because. he for the moment gives up questions of composition and concerns himself with the action of forces? Does the work of a physiologist belong under chemistry because he for a time studies the composition of the digestive fluids of the human body? Does the work of a petrographer fall under chemistry when he uses chemical reagents in the analysis of his rocks, or under physics when he uses Nichols prisms and polarized light in the determination of his minerals? When a man calculates the orbit of a comet from three observations of its position in the heavens, is his work to be classed under mathematics or under astronomy?

The principle which must guide us in assigning a place to all such work is that it must be classed according to the object to which it is directed, not according to the means by which it is carried on, nor according to the detail with which it is elaborated. In the last case mentioned if the object sought is a fuller knowledge of a comet, the work belongs under astronomy, even though the means used in order to reach the object are mathematical. In all such questions it is the object and not the methods, the end and not the means, which determines the classification of the work done and of the man who does it. Utter confusion would result from any other plan of classification. Hence there is good and sufficient reason for saying that the description of the Front Range given below, and all the other descriptions and phrases that I have here introduced, are geographical descriptions and phrases, because their object has been the presentation of the facts regarding existing land forms, even if in gaining this object various facts regarding rock structures and past processes were freely employed whenever they were helpful. All of the descriptions here cited were carefully phrased in such a way as to lead up to existing facts. Emphasis was always intentionally placed on existing features and not on past conditions or processes, except in so far as these directly aid in appreciating present conditions. All geological matters which have no bearing on existing facts were excluded. No mention was made of geological periods in terms of their names, ilor was any account given of the succession of events in past time, except in so far as such succession may throw light on the nature of the facts now visible. 
Let me show explicitly how closely pertinent, how directly helpful every element of the description of the Front Range is in forming a just conception of the existing landscape. The range was described as "a highland of disordered and generally resistant crystalline rocks, which shows signs of having been long ago worn down from its initially greater mass to a surface of faint relief, slowly depressed and more or less broadly buried under a heavy cover of sedimentary strata." That condensed statement gives us a sufficient introductory understanding of the compound structural mass with which we have to deal. Next: "As the result of a general uplift a part of the compound mass west of a pronounced monoclinal displacement along a north-south line came to stand above the rest, and thus the province of the mountains on the west was marked off from that of the less uplifted plains on the east." This statement makes clear the attitude in which the compound mass was placed at the beginning of an important cycle of erosion, the work of which is at once intimated as follows: "The form of the highland shows that the whole region advanced far through the cycle of erosion introduced by the monoclinal uplift." From this the hearer may easily infer what is at once directly stated, namely, "that the resistant underlying crystalline rocks of the mountains area were stripped of their cover and worn down to a gently rolling peneplain, diversified with irregularly scattered monadnocks rising singly or in groups with a relief of from 500 to 2,500 feet." This is a most pertinent matter, for herein we find the explanatory conception of the broad surface of erosion, which is now seen in the highland of the Front Range. It might have been expected that scattered monadnocks would survive, even though much of the surface was peneplained, because the crystalline rocks were described as generally resistant, thus implying the occurrence of some variation in their resistance; and again that the surviving monadnocks would be irregularly scattered singly or in groups, because the structure of the crystallines was briefly described as "disordered." Had systematic trends characterized the arrangement of the rocks, and had pronounced difference of resistance characterized their composition, those structures would have been mentioned earlier; the absence of such mention indicates the absence of such structures and suggests the inference of scattered monadnocks. Although no explicit statement is made as to what happened during the same cycle of erosion in the plains area, it is easily inferred that the weak strata there exposed must have been worn down to extremely faint relief, because the resistant crystallines of the mountains area are explicitly stated to have been as a whole worn down to a gently rolling peneplain. 
To continue: "The valleys of the highland show that a renewed uplift gave the whole region a greater altitude than before, with a gentle uparching along a north-south axis in the mountain area 15 or 20 miles west of the monocline, whereby the peneplain with its monadnocks gained the highland altitude of the present Front Range, the crest of the up-arching and the monadnocks that happened to stand near the crest defining in a general way the crest of the range." All of this is immediately pertinent in presenting in an explanatory manner the form and attitude of the highland at the beginning of the present cycle, this initial form being the penultimate form of the preceding cycle, now uplifted to a new position. The description goes on further as follows: "The weaker strata of the plains are now again worn down to small relief," and from this we gain a general conception of the denuded plains truncating the monoclinal strata near the mountain border and stretching eastward indefinitely; but "the harder crystalline rocks of the mountainous highland are only submaturely dissected by normal submature or mature valleys"- that is, parts of the peneplain, surmounted by its monadnocks, must still be recognizable in rolling highlands between valleys, some of which, being described as submature, must be conceived as narrow and rock-walled, while others, described as mature, must be imagined as being more open, with waste-cloaked sides. The closing clause states that "the higher parts of the valleys have recently been strongly glaciated," and this at once suggests the excavation of cirques in the valley heads among the loftier monadnocks along the range crest and the transformation of the upper valleys into overdeepened and widened glacial troughs with oversteepened sides.

\section{THE EXPANSION OF CONDENSED PHRASES INTO THEIR FULL MEANING}

It must be apparent from the foregoing that the true geographical value of a condensed explanatory description can be reached only by expanding or translating each technical term or phrase into its full meaning with respect to the features of the existing landscape. The more successfully the translation is made the more fully will the reader's attention be brought forward from past conditions and processes to existing forms, and the more fully will the really geographical nature of this apparently geological description stand forth. An experienced reader can translate at sight; an inexperienced reader must give some time before he can explicitly state all the meaning that technical terms and phrases implicitly contain. In either case an attentive study will show that every element of the explanatory description of the Front Range bears immediately and helpfully on its present form, with the possible exception of a statement 
made in the second or third line, namely, "a highland of disordered rocks, which shows signs of having been long ago worn down from its initially greater mass to a surface of faint relief, slowly depressed and broadly buried." Of what value, one may ask, is this reference to a long cycle of ancient erosion and planation before the depression and burial of the worn-down mass, and hence long before its monoclinal uplift and later erosion? In answer it may be said that the mention of ancient planation of the crystallines before the covering strata were laid down was intentionally introduced, because it is a factor of prime geographical significance in leading to an intelligent conception of one of the most characteristic features of the Front Range, namely, its abrupt and almost rectilinear border toward the plains, for if we imagine a compound mass, of which the under member was a worn-down body of disordered and resistant crystallines, while the upper member was a heavy series of sedimentary strata, and then conceive it to suffer monoclinal deformation, peneplanation, renewed uplift, and renewed erosion, by which the weaker strata east of the monocline are again peneplained, while the resistant rocks of the mountains are only submaturely dissected, the mountain area must then exhibit along its border a stripped part of the surface that was long ago worn down to faint relief, and hence the mountainous highland today must have an abrupt and rectilinear margin, in which the stripped part of the surface of ancient planation, tilted into a monoclinal slope, is exposed between the higher peneplain of the hard-rock highlands and the newer and lower peneplain of the weak-rock plains. The stripped planation surface of the mountain front will, of course, be cut down by numerous revived streams, where their valleys open from the highland; thus the continuous mountain border is transformed into a series of trapezoidal or triangular facets, of which the upper part will be somewhat the worse for wear, and the lower part may be still more or less covered by the basal members of the tilted plains strata; but for all that the mountain front, thus explained, must be conceived as abrupt and essentially rectilinear. The mountain front is indeed a great fragment of a fine geographical fossil, in the sense of being part of an ancient surface, either a land area or a sea floor, long preserved by depression and burial, and now, like many smaller fossil, brought to light by uplift and erosion, its higher extension completely destroyed and its exposed belt somewhat weather-beaten, while its lowest, deep-lying part still remains buried. It is a pleasure to put on record at this time and place that it was my friend and classmate, the lamented Archibald R. Marvine, who, as a member of Whitney's party in 1869 and of Hayden's Survey a few years later, first recognized the origin and the significance of this ancient surface of erosion, 
In view of the foregoing, I am disposed to maintain the truly geographical nature of the description, beginning with: "The Front Range is a highland of disordered and generally resistant crystalline rocks," and ending with, "submaturely disseeted by normal submature and mature valleys, the higher parts of which have recently been strongly glaciated." Its object is geographical throughout, in the sense that it strives to present a truthful picture of the existing mountains. It is geographical for just the same reason that a geographical quality is found in the phrases: "Here is a dissected volcano," "there is an uplifted and slightly dissected delta," "that is a peneplain, uplifted and gently tilted, maturely dissected and recently heavily glaciated." Indeed the description of the Front Range is geographical for the same reason that the still shorter phrases, "here is a delta," "there is a volcano," "that is a peneplain," are geographical. True, the description of the Front Range was much longer than the brief, four-word phrase last cited; true, the description of the Front Range made repeated and explicit mention of various rock structures and past processes, while rock structures and past processes are only implicitly suggested in such phrases as "this is a delta," "that is a volcano," "there is a peneplain." But the longer description and the shorter phrases are all geographical because their object is the description of existing features of the earth's surface. In this case and everywhere else it is the object in view and not any distinction between brevity and length, or between the implicit and explicit mention of rock structures and past processes, that should serve to determine whether a description belongs under geology or geography.

We may indeed fairly insist that if the description of the Front Range is not geographical, then the familiar geographical terms, delta, volcano, and peneplain, must also be withdrawn from geography, and that is manifestly absurd. There can surely be no cuestion that these terms imply structure and process. When we say "delta" we do not mean merely low land near a river mouth; there is abundance of low land near river mouths along the Gulf coast of the Southern States that can not be included under this term. Whatever delta may have originally meant, it surely in this modern day means a deposit of river-brought land-waste, laid down with suggestive form and a highly significant stratified structure in relatively quiet water at a river mouth, where the efficiency of the river as a transporting agent is rather suddenly decreased; and, furthermore, a delta, thus understood, is perfectly well known not to be the product of a momentary action; its production has required a significant measure of 
past time. Again, when we say "volcano" we mean the product of certain processes acting through a certain measure of time, as a result of which the thing produced has certain peculiarities of composition, structure, and form. Similarly, when we say "peneplain" we imply, in the mere mention of the term, the action of normal erosive processes on structures of any kind for a vast period of time, as well the land surface of small relief which the erosive processes have produced and which transects the underground structures indifferently. Structure and process are thus seen to be involved in the meaning of several familiar geographical terms in essentially the same manner that they are involved in more elaborate explanatory descriptions, such as that quoted for the Front Range. It would be absurd to regard the terms delta, volcano, and peneplain as geological instead of as geographical terms; hence it can not be reasonable to regard the description of the Front Range as geological instead of geographical.

\section{TECHNIOAL EXPLANATURY TREATMENT OF LAND FORMS}

On the other hand, the description of the Front Range is not a good sample of elementary geography, nor of empirical geography, nor of fullfledged geography. The description was intentionally phrased to give an example of explanatory treatment as contracted with empirical treatment; of advanced grade and of technical style as contrasted with elementary grade and popular style; of condensed form instead of detailed form, and it was intentionally restricted to one subdivision of the inorganic or physiographic side of geography, namely, to that subdivision which is concerned with land forms; all other inorganic subdivisions, such as oceanic problems or climatic conditions, as well as all of the other side of geography, namely, its ontographic relations-the relations into which vegetable, animal, and human inhabitants enter with their inorganic environment-were intentionally omitted. The description being of advanced grade, it may well be impenetrable to juvenile geographers, but it is not thereby transferred to geology. Its advanced phrasing necessarily requires on the part of those for whom it was written a familiarity with various rocks, structures, and processes, so that a brief mention shall lead to an easy understanding of the landscape in which they result. Being of explanatory treatment, it may seem unfamiliar to empirical geographers, who vainly wish to limit their study to the earth's present. surface, and who think that they have nothing to do with underground rock structure and past processes; but the description is not thereby lost to geography. Being condensed in form, its understanding may demand close attention if it is spoken or repeated reading if it is printed, for all 
its implications have to be translated and expanded from conditions of rock structure and past processes into concepts of surface form, and this requires training. Being concerned only with land forms, the description is lacking in climatic elements and ontographic relations, and it is therefore incompletely geographical in the sense that the treatment of a section of a subject incompletely represents the whole subject; but it belongs none the less under geography, because it is explanatory, advanced, condensed, and incomplete. Hence I propose still to regard this explanatory, condensed description as a geographical description.

\section{Part II. The Necessity of explanatory Treatment in modern GeograPhy}

\section{EMPIRICAL AND EXPLANATORY GEOGRAPHIOAL DESCRIPTIONS}

In spite of all that has been said thus far, some of my more conservative hearers may regard all the explanatory descriptions thus far cited as belonging under geology, because, being explanatory, such descriptions necessarily have to do with the past, and in the mind of these hearers nothing that has to do with the past deserves to be classed under geography. There is, I fear, some reason for thinking that most of those who thus object to the explanatory method of geographical description and who reject such a description as that given above for the Front Range from geography were educated in the older-fashioned empirical school, and have never given much attention to the newer-fashioned and more rational method of geographical presentation. To them geography is only an empirical subject-that is, it deals only with immediately observable facts, independent of all theoretical explanations. Naturally, then, if they meet a geographical problem, treated in an explanatory manner, particularly if it includes an account of a group of land forms treated in terms of rock structure, erosional process, and stage of erosion reached, they do not recognize it as geographical and think it belongs to some other subject; but it is geographical all the same, because its object is the description of the visible landscape.

Empirical geographers may, however, object to this assertion, and ask why geography should be treated in an explanatory instead of in an empirical manner; why it should thus be made to trespass so far on geology as to include considerations of underground structures and past processes, instead of being content to describe visible forms directly in the, good old-fashioned, superficial, empirical method, without making so much ado about it. A reason often given for the introduction of the modern and more penetrating rational method is that explanatory descrip- 
tions are more interesting and more easily remembered than empirical descriptions. This is perfectly true, but it is not the whole or the chief truth. Let it here be understood that the duty of a geographer is twosided; he must first gain a correct knowledge and he must then give an intelligible description of the facts of his subject; and it can not be doubted for a moment by any geographer who has carefully tried to fulfill both sides of his duty that both the investigation and the investigator are greatly aided by the adoption of an explanatory method. I believe this to be true in all branches of geography, and particularly in the study of land forms. Hence the strongest reason for advancing from the older-fashioned empirical treatment to the newer-fashioned explanatory treatment lies in the greater power of the newer treatment, in the power of deeper penetration on the part of the investigator into the real nature of the facts concerned, and, more particularly in relation to our present discussion, in the power of clearer and more intelligible presentation of the described landscape to the properly qualified reader. The ground for this statement, which is here still made with special reference to land forms, but which is I believe equally true for all divisions of geography, organic and inorganic, may be more fully appreciated by considering what follows.

\section{ADVANTAGES OF EXPLANATORY TREATMENT}

Whenever an explorer desires to describe the features of the landscape that he traverses, he must necessarily describe them in terms of previously acquired mental concepts, and these mental concepts may be called his mental geographical equipment; furthermore, after an explorer has written and printed a report on his explorations, his descriptions can be properly understood only by those readers who are in possession of essentially the same kind of mental geographical equipment as the one that the explorer possessed. Now, there are in use today two unlike kinds of mental geographical equipments for the descriptions of land forms-one made up of empirical concepts, independent of all theory, the other of explanatory concepts, which are absolutely dependent on theory. Empirical concepts must be learned by heart, for they are not reasonably connected by an understanding of the origin of the forms that they represent; they are simply matters of observational experience arbitrarily combined, too often after the fashion of these fanciful artistic compositions, picturing imaginary landscapes, which one used to see on an early page of geographical text books, and in which mountains and tablelands, waterfalls, and deltas were so marvelously juxtaposed. Explanatory concepts are, on the contrary, reasonably associated with one another and with the general principles from which they are derived, so that they are easily remembered in spite of their great variety. 
Empirical concepts-I still speak especially regarding land formsare known only as far as direct observation can penetrate, and they are therefore necessarily superficial in space, short-sighted in time, and rigid in definition. Explanatory concepts are known through and through, fore and aft: the farther side of the concept of a ridge is seen just as well as the near side, by the eye of the imagination, which takes any point of view that it desires; the inside of the ridge is seen as well as the outside, the past and the future forms of the ridge as well as the present form, for all these concepts are avowedly mental concepts only and not matters of fact. Explanatory concepts are, moreover, most elastic and adaptable, so that they may be easily made to match the facts of nature. Such concepts may be fanciful in the sense of not being necessarily counterparts of any natural forms; they may be erroneous in the sense of being incorrectly deduced from unsafe generalizations, and such chances of error must be recognized and guarded against. But the prime fact. remains that explanatory concepts, deduced from general principles, are much more intimately and reasonably knowable than empirical concepts or even than facts of observation usually are, and in this quality of being intimately and reasonably knowable lies their highest value. It is as if one located them by sighting from many different points along the path of time, and thus fixed their position by the intersection of many converging lines of sight, while empirical concepts are located only by a single line of sight running in one direction from the viewpoint of the momentary present.

\section{GROUNDS OF CHOICE BETWEEN EMPIRICAL AND EXPLANATORY METHODS}

Let it, however, be clearly understood that the object of explanatory geographical descriptions is not the presentation of inferred facts concerning the past history of the earth, but the presentation of the most carefully defined concepts concerning the present earth. This is essential. The land forms of today may, of course, be used, just as stratified rocks or fossil prints are used, to constitute an observational basis for inferences regarding the past history of the earth, and the study of land forms with this object is a part of geology just as much so as the similar study of strata or of fossils, for it is, as already stated, the object of a study and not the thing studied or the method of studying it that determines the place of the study in a classification of the sciences. Inferences based on. the form of the upland of southern New England as to the relatively modern date of its uplift from a long residence at a lower altitude belong under geology; but descriptions of the uplands of southern New England as the product of prolonged erosion during a lower stand of the land, fol- 
lowed by uplift and by renewed erosion consequent thereon, belong under geography.

When it is perceived that there are two kinds of geographical equipment possible, and that both kinds are in use, it is evident that both must he learned by all who wish to understand current geographical literature. But when it comes to writing a description of an observed landscape the writer should, unless he is writing so carelessly that he combines the two equipments in a semi-conscious or accidental manner, consistently use either one equipment or the other. He has therefore to determine which one of the two equipments he will employ, and he will most wisely choose the one that gives the greatest aid in his practical work. Hence he ought to make conscious experiment with both methods, and his experiments ought, for the best results, to be made in duplicate-that is, several different landscapes ought to be treated in each of the two methods-and the resulting descriptions should be impartially compared. At the present stage in the evolution of geographical science nothing is more important in the education of a young geographer than intentional, impartial experiment with both these contrasted methods of description.

But it often happens that inborn temperament and habit of thought as determined by education are more influential than impartial judgment in making choice between the two methods. 'The empiricist objects to explanatory concepts because of their theoretical nature, their frequent complication, and their possible error; he prefers concepts of a simpler kind, based directly on observed forms and independent of all theory, because they are then-as he thinks-so easily conceived and so safe, or because they are so generally understood, and perhaps still more because they were taught to him years before. On the other hand, the rationalist finds empirical concepts insufficient in providing accurate and intelligible descriptions; he prefers explanatory concepts because, by the very reason of their complexity, they better represent the complexity of actual land forms and of increasing geographical knowledge. He frankly recognizes that explanatory concepts are relatively complicated, and he well knows that they must be made familiar by careful study before they can be easily and effectively used; he recognizes that if they are uncertain they must be used only in a tentative way until they are safely established; but he is willing to give time to establishing them and to familiarizing himself with them, hecause they prove to be so extremely helpful in his work.

The empiricist is apt to treat explanatory concepts as if they were mere fancies; he insists that he does not wish to go beyond matters of fact. 'The rationalist recognizes that while explanatory concepts are truly' the 
product of the imagination and not directly of observation, they can be rightly conceived only by use of a trained scientific imagination, for they are careful deductions from successful theories, the theories being based on abundant observation and induction, and the deductions being tested by repeated confrontation with facts. For this reason explanatory concepts represent the sum of pertinent knowledge thus far gathered, while empirical concepts represent only the beginning of the sum, for explanatory concepts contain all that is valuable in empirical concepts and a great deal more besides. Inborn temperament and habit of thought as determined by education may truly have much to do in determining which kind of equipment a geographer will use; but these vestiges of the past are not always our best guides when we have to make judgments regarding the future.

\section{TREND OF MODERN GEOGRAPHY TOWARDS EYPLANATORY TREATMENT}

The direction of modern progress in all branches of geography is distinctly toward the fuller development and the more general use of a mental equipment consisting of explanatory concepts. No one who compares geographical writings of fifty years ago and of the last ten or twenty years can fail to recognize this manifest tendency. If time permitted, an interesting story could be here introduced regarding the gradual progress from the old-fashioned empirical description of such features as shorelines toward their more thorough-going, more comprehensive, more advanced and mature, modern and explanatory treatment, or from the old-fashioned, blindly empirical description of our prairies to their newer-fashioned, illuminating, explanatory description, or from the meaningless, barren, empirical description of mountains in the older texts to thein highly significant, fruitful, explanatory description in more modern books. No one who is aware of the change thus made and of the great progress that it marks is willing to return from the newer-fashioned to the older-fashioned method of treating land forms. Geography is today no longer the backward child that it was a century ago; it is growing up, even if it has not yet shown many signs of so rapid, indeed of so precocious a development as that of its younger sister, geology. The chief cause of the modern progress of geography is not the discovery of more mountains, more capes, more rivers, more islands; it is not the more elaborate enumeration of the kinds of plants and animals that inhabit a region, nor the fuller account of the location of cities and the boundaries of states, but the adoption, in the treatment of all geographical facts, of the evolutionary philosophy that has so profoundly modified all natural sciences; in a word, the adoption of explanatory theoretical concepts and terms for the description of observed facts. 
It may be fairly asserted that practically every trained geographer, who has in recent years acquired a good understanding of both the ejnpirical and the explanatory kinds of mental equipment and who has made a faithful comparison of their efficiency in the description of actual landscapes, has decided in favor of the explanatory equipment. Explanatory description is rapidly gaining acceptance wherever it is understood. Geographers of the older school still, naturally enough, prefer the empirical methods in which they were originally trained; yet even they use certain explanatory terms, such as sea-cliff, moraine, and many others, in a semi-conscious way; but they do not intentionally and whole-heartedly adopt the principle of explanatory description and carry it systematically forward to its full application. On the other hand, the most pronounced rationalist will not infrequently meet a feature of a landscape for which he can not provide a safe explanatory counterpart because he is not fully assured that he understands its origin. In such a case he may say, "It looks as if" it were so and so. In using such a qualifying phrase he frankly presents his best attempt at an explanatory description, and at the same time shows that he is in doubt about its correctness. He may indeed not infrequently encounter features for which he has no satisfactory explanation at all; he must then with equal frankness fall back on an empirical description, but always with expressed discontent; always with the hope and the effort to find the origin of the form and then to give it a properly explanatory description.

\section{LIMITATION OF GEOLOGICAL ELEMENTS IN GEOGRAPHICAL DESCRIPTIONS}

Let me in returning more particularly to land forms note again that what is here called the explanatory description of a landscape includes, as has been stated already, simply so many of the inferred facts of past time as bear helpfully on the understanding and description of the observed facts of present time. If this still savors of geology it may be urged that all ground for classing such a treatment under geology instead of under geography is withdrawn when the words "and no more" are added, thus: "The explanatory description of a landscape includes simply so many, and no more of the inferred facts of past time as bear helpfully on the understanding and description of the observed facts of the present time." There is, of course, no break in the backward stretch of the chain of causation from the geographical present into the geological past, but there is a limit soon reached as to the number of back-reaching links in the endless chain which are practically helpful in the description of existing forms-that is, helpful in forming mental counterparts of existing forms. German geographers are, in my judgment, inclined to introduce 
too many links, and thus to encumber their geographical essays with so many inferred facts of remotely past occurrence, little related to present facts, that the reader's attention is distracted from instead of concentrated on the facts of present form.

Let me emphasize this principle by pointing out that the exclusion of irrelevant geological matter requires careful consideration. There is too frequently a tendency among geographers of the modern or evolutionary school to make mention of geological technicalities, which, however important they may be in geology, are unessential and irrelevant in geography. Many geographers would, for example, introduce into such a description as that given above for the Colorado Front Range petrographical and geological names for the deformed and generally resistant crystalline rocks of the highlands, and for the members of the heavy cover of sedimentaries now seen in the adjacent plains, and they would mention also the geological dates of the early planation, of the monoclinal deformation, of the later peneplanation, and of the final uplift of the district to its present altitude. All such matters are truly essential in a geological description, but they are unessential, irrelevant, distracting, and obstructive in a geographical description. If a better understanding of the appearance of the existing landscape can be gained by adding any one of these geological terms, then let it, of course, be added at once; but if not, let it be as carefully excluded.

It may well be that in his preparation for writing the description of a mountain range a geographer has occasion to examine many geological reports, in which he will repeatedly come upon such matters as names of formation, dates of unconformities and deformations, and so on. When he finally abstracts those parts of his accumulated information, which are to serve for a truly geographical description, all names of formation which imply geological dates and all names of fossils and of rare minerals will be carefully excluded. True, if a geographer wishes to make his geographical description serviceable to geologists, he may well enough include some mention of purely geological matters that are geographically irrelevant; but in the same way he might make his geographical essay useful to mathematicians by including some mention of the method of calculating logarithmic tables, or to classical philologists by adding some remarks on the increase of certain Latin nouns in the genitive. All such matters have their value somewhere and are all interesting to those who are interested in them; but none of them deserve a place in a geographical description unless they aid in the object of that description, namely, the portrayal of the existing landscape. If some of my hearers are skeptical cn this point let them settle their doubts by making critical trials of pure 
and of mixed geographical descriptions, and let them measure the strictly geographical value of their descriptions by giving a single-minded attention to their success in providing strictly geographical pictures. Naturally if a purely geographical description, from which geological terms are absent, is read by a geologist who wishes to know the names of rock formations he will find it unsatisfactory; but it is not for the purpose of giving satisfaction to a geologist that geographical descriptions are prepared. If, on the other hand, a geographer maintains that he as a geographer gains satisfaction from the mention of a geological formation by its technical date-name, let him try to specify exactly the way in which such mention gives him geographical satisfaction and he will find much difficulty in doing so. Let it, however, be clearly understood that if any writer, be he geographer or geologist, wishes to add to a geographical description supplementary information on any subject, such as the names of geological formations, a rule for the extraction of cube roots, or advice on the use of Latin subjunctives, he is, of course, perfectly free to do so; but do not let him think that in so doing he is making himself or his description more geographical.

The nature of a truly geographical description of explanatory style may be emphasized by pointing out the nature of a proper geological description. In a geological description each fact of existing structure serves, explicitly or implicitly, as a basis for inferences regarding past conditions and processes of deposition, deformation, intrusion, denudation, or other process, and each inference as to the conditions and processes of past time should be referred to its proper place in time-sequence in order to give due emphasis to the essentially historical aspect of geological science. Between this sort of a description and a properly geographical description there are abundant contrasts.

\section{THE GEOLOGICAL NATURE OF GERTAIN GEOGRAPHICAL STUDIES}

There are, however, articles of a certain kind, often written by geographers and published in geographical journals, and therefore commonly associated with geography, which more logically belong with geology. These are articles which are concerned with the past action of various processes in producing different kinds of land forms, and in which the manner of action of the processes and the nature of the forms that they produce is still under discussion, because the processes have not in this respect been fully investigated by those scientists who concern themselves chiefly with the operations of past time. A hundred years ago the disputed action of rivers in carving valleys occupied many pages of this kind; today the disputed action of glaciers in modifying land forms pro- 
vides material for many similar pages. In writing such articles the geographer becomes for the time being and in a very limited way a geologist, for he is not trying to describe present forms, but to discover how certain agencies have acted in past time. As long as such problems are in discussion attention is naturally and properly more directed to past processes than to present results, and the investigation of past processes as such is evidently a geological matter. It is only after problematic processes are satisfactorily settled that they can be safely employed in explanatory descriptions of present forms; only then can the geographer return from his excursion on geological fields to his own science. Similarly a chemist, who wishes to filter or to weigh a precipitate and who finds no satisfactory methods of performing this purely physical process described in the standard works on physics, must for a while stop being a chemist and turn his attention to inventing a mechanical device for filtering or weighing things, thus transforming himself for the time being and to a limited extent into a physicist; but the invention once made and put to use as a means of finding out the composition of things, the investigator becomes a chemist again.

It is through considerations of this kind that one becomes convinced of the necessity of explanatory treatment in modern geography.

Part III. The Diminution of apparently geological Matter in GEOGRAPHICAL DESCRIPTIONS

THE ADVANTAGE OF TERMB OVER PHRAgES

In view of the demonstrations given in the foregoing pages, it should be understood that the place of a description in a classification of the sciences is determined by its object rather than by the means employed in reaching the object, and it should be recognized that explanatory geographical descriptions are of greater value than empirical descriptions; and from these conclusions it further ensues that the description of the Front Range given at the outset is not geology but good geography. If one grants the reasonable postulates with which the demonstrations begin and follows the demonstrations through their logical course, the conclusion just stated is inevitable; but do we not all know that many of us, especially our opponents, are not inclined to grant reasonable postulates, and that some opponents are unwilling to follow. logical demonstrations? Do we not furthermore all know the opinion of the man who is convinced against his will? In view, then, of the difficulty of demonstrating to geologists the essentially geographical character of an apparently geological description, let us adopt another method of reaching a common 
understanding regarding the ground to be cultivated and the means to be employed in geography, the older but less developed sister science of geology.

It has already been shown that various terms, such as delta and volcano, which undoubtedly belong under geography, are really only concise names for things that result from a more or less complicated series of processes acting through a Ionger or shorter period of time, so that if the terms were expanded into their full meaning the resulting phrases would be classified under geology by those of us who would place in that science the explanatory account of the Front Range with which this address began. Let me illustrate this point more fully.

If instead of saying "volcano" one should expand this simple word into its whole meaning, there would be much to be told about the long continued action of a whole series of past processes; there would first be an explicit statement about the prevolcanic foundation; then something about the initial stages of eruption, with their associated explosions, earthquakes, growing cinder cones, outspreading lava flows, and farcarried ash showers; there would be mention of intermediate periods of erosion, with the outwash and deposition of torrent-borne volcanic agglomerates on the neighboring lower lands; of renewed volcanic activity, in which dikes split their way upward, or in which the earlier volcanic summit is engulfed only to be built up again higher than before, with renewed explosive outbursts, with lava flows and ash showers that fill the valleys eroded in the earlier cone, and so on over and over again, for a volcano is a complicated affair. Surely no self-respecting volcano that has gone through all these violent throes of growth and all these periods of apparent exhaustion would be content to be thought of as a ready-made article without a past. Indeed if a geographer says "volcano" without more or less distinctly conceiving all this complicated series of past processes he confesses himself deficient in scientific inauguration. Furthermore, no volcano that has properly played its destructive part in organic evolution would be satisfied with an account which made no mention of the way eruptions had repeatedly overwhelmed the organic inhabitants of its district, burning and burying successive populations that had mistaken the foundation or the flanks of the cone for a safe habitation. Indeed, when we properly link volcanic growth with organic evolution, we may come to discover that the existing population of a large volcanic district recently and repeatedly overwhelmed by lavas and ashes, as in central Mexico, is chiefly made up of such plants and animals as could repeatedly return after repeated destructions and expulsions, and hence that in such a population we should find for the most part active settlers, while slow VIII-BULI. Grox. Soc. Ax., Vor. 23, 1911 
cotonizers would have been killed or driven out and never had a chance to return. True, when a beginner in geography first meets the word volcano and learns likely enough that it is a burning mountain he gains no very full understanding of all these dramatic changes, just as when he first studies history' he gains no real appreciation of all the long continued oppressions and struggles that eventually culminate in the outburst of a revolution, of which he learns hardly more than the date. But does volcano truly mean anything less than all the complication of events that is here briefly sketched? Must not a mature and thoughtful geographer strive when he says "volcano" to visualize the long succession of active eruptions and quiescent periods, of upbuildings and downwearings, of organic destructions and recolonizations which the single word, volcano, implies; must he not conceive all this long succession through which alone he can come to know what the existing volcano really is? And just in the same way must not the mature historian go far beyond the schoolboy in conjuring up slow-moving pictures of the past when he speaks of a revolution, if he wishes to know what the revolution really was?

It is the same with the brief phrase, "a mature river." There was a time not very long ago when a river with a maturely graded course could be regarded, even by mature geographers, as simply an existing thing without their feeling any concern about the long series of changes which must inevitably have run their course before maturity could be reached; but that time is not ours. No modern geographer who recognizes the evolution of the present from the past-and no modern geographer can fail to do that-no modern geographer can escape from imagining the young stages of a river as preceding the mature in order properly to appreciate the mature stages. Still more, if one speaks in concise terms of "a meandering valley maturely incised in an uplifted peneplain of disordered structure," must the appreciative understanding of this descriptive phrase build up the conception of the present on a long succession of past events, and indeed not only on a succession of inorganic events, but of organic events as well; for, as Woodworth first pointed out and as Cowles has later so fully shown, there is a most intimate, systematic, and essential correlation between these inorganic changes and the organic changes that lead up to the present organic population of an uplifted peneplain of disordered structure, traversed by an incised meandering valley, and no proper account of the present populations can be given without an appreciation of their past. Yet surely a geographer who understands the abundant implications of the term volcano may use it without being considered as encroaching on geological grounds, and he may even speak of an uplifted peneplain traversed by an incised mean- 
dering valley without exciting remark as being an overventurous trespasser, although it is plain that the real meaning of the single term volcano, as well as of the explanatory descriptive phrase, is crammed full of past conditions and processes and changes. But if he explicitly paraphrases those past changes, as was done in case of the long explanatory account of the Front Range, he is regarded as having left his proper field for that of geology.

The lesson from this is clear enough. If, instead of describing the structures and reciting the succession of events that lead up to the existing forms which are treated in the explanatory description of the Front Range, we had a single term which immediately indicated the general result of all this succession, the term might be used with all its implications and yet without exciting the fear that in using it geographers were metamorphosing themselves into geologists. True, if the Front Range were the only example of its kind, it would be hardly worth while to invent a term to name it; but such is by no means the case. Similar successions of events on similar structures producing similar forms are well known elsewhere, and a generic term for all of them, with specific adjectives to indicate their different expressions, would be very helpful in geographical descriptions. Let it be remembered that in inventing and using a single term for the casy statement of a complicated idea or type, geographers would only be following the example set by workers in other sciences. Consider the biological term metabolism; instead of attempting here to define its meaning, we may accept the assurance of biologists that this word is packed full of elaborate meaning, and that its use saves much round-about paraphrasing. Geographers might well follow the example of their fellow-scientists in this respect. Allow me to recount a recent experiment in the invention of a systematic name for such district as that of the Colorado Front Range.

\section{AN EXPERIMEN'IN IN THE INVENTION OF A TERM}

I) uring a geographical pilgrimage from Ireland to Italy that I conducted in the summer of 1911, several of the pilgrims tried to find a term that might be used to name a region of composite structure, consisting of an older undermass, usually made up of deformed crystalline rocks, that had been long ago worn down to small relief and that was then depressed, submerged, and buried beneath a heavy overmass of stratified deposits, the composite mass then being uplifted and tilted, the tilted mass being truncated across its double structure by renewed erosion, and in this worndown condition rather evenly uplifted into a new cycle of destructive evolution. The older mass of such a structure would in its relation to the 
younger part possess the essential features of the Front Range in central Colorado, of central Wisconsin, of eastern Devonshire, of eastern Brittany, of the western and northern border, of the central highland of France, of the northeastern extension of this highland, known as the Morvan, of the western side of the Vosges, of the eastern side of the Odenwald and the Schwarzwald. In northern Arizona there is an ideally perfect example of such a structure, which instead of being uplifted in modern geological times into a new cycle of erosion, was in ancient geological times depressed and buried under about two miles of strata, the triple mass being afterward uplifted and so deeply eroded that the buried double mass is shown in a superb natural section at the bottom of the Grand Canyon of the Colorado. It would be helpful to have a name that should be used in talking about the recurrent geographical features of all such structurally similar masses, the name being applied more particularly to the area of the older resistant rocks which ordinarily stand in relief as an upland or highland in the current cycle, but at the same time being used to indicate the relation in which the upland or highland stands to the adjacent lower area of inclined stratified rocks. Structurally considered, the problem here involved has been called by one of my students the problem of intersecting peneplains; but that is a phrase, not a name; so the search for a name had to be continued during our summer pilgrimage and for some time without success, until one day, patience being exhausted, I exclaimed: "Let us call the thing a skiou!" "What is a skiou ?" asked my companions. "A skiou is the thing we have been talking about." "What is the origin of the word ?" "It hasn't any origin; it is made up from nothing, like the words "gas" and "boss ;" let us use it till we find something better." "How is it spelled ?" "It never has been spelled, but it is going to be spelled s-k-i-o-u; its plural shall be in s, and its gender is masculine." This last declaration, be it noted, was made to satisfy my French and German companions. Thereupon skiou was used by all of us in a provisional way, and one of the party illustrated a number of different kinds of skious by a series of block diagrams, in which the essential elements were given different values. When a new pilgrim joined us, we talked familiarly of skious in his presence, just as petrographers talk of eleolite-syenites, or hypersthene-andesites, wherever they are; thereupon the newcomer would lean toward his neighbor and ask in an undertone, "What is a skiou?" and his neighbor would say aloud, "Don't you know what a skiou is! Say, fellows, here is a man who never heard of a skiou." Thus we developed a sort of initiation ceremony, and when the next newcomer arrived it was for his predecessor to exclaim, "What! have you never heard of a skiou?" 
But the serious side of our fun was that the term served its purpose; it saved time in our discussions and saved space in our note books; but it may now be supplanted by a more satisfactory term, to wit, morvan, the name of the northeastern extension of the central highland of France, which is, as already mentioned, an excellent example of the skiou kind. True, the French Morvan, from which the covering strata dip very gently to the north, is limited on the east and west by faults, and hence its extension along the strike of the covering strata is of moderate measure; but this will be regarded as an individual feature; other morvans may have a greater extension and may be terminated in other ways. Like meander and monadnock, morvan may be written with a small $\mathrm{m}$, to indicate its generic value, and it may be pronounced by us in plain English fashion, like Paris and France.

\section{MORVANS OF DIFFERENT' KINDS}

A few days' exercise on morvans will suffice to form acquaintance with many imaginary examples, each one possibly the counterpart of an actual region. Such exercise enriches the mental equipment of a geographer by providing him with various sorts of morvans; one, for instance, may be imagined in which the undermass consists of deformed and resistant crystalline rocks; the first planation was perfectly accomplished, the covering strata possessed abundant thickness and variable resistance, the lowest member being weak; then the uplift tilted the double mass to the north at a small angle; the second planation was less complete than the first, the broad uplift which introduced the present cycle was of moderate measure, and the stage of erosion now reached is early mature in the resistant undermass, and late mature in the covering strata to the north, on which a series of alternating cuestas and lowlands are now developed along the strike of the stronger and weaker members. Now, if the covering strata are imagined as faulted down on the east and west at the time of the gentle northward tilting, such a morvan would fairly represent the original morvan itself.

Another example might retain a considerable relief when depression and burial occurred, and might be given a moderately strong tilting to the east, north, and south when uplift took place; it might then be for the most part well worn down, yet retain a number of smaller and larger monadnocks on its hardest rocks; it might next be broadly uplifted and, in the cycle thus introduced, the resistant undermass of disordered crystallines might be maturely dissected while the weak lower members of the covering strata were reduced to a new lowland, and this example would then represent the uplands of Devonshire near their eastern border. If to 
such a series of events we add a recent and slight depression, whereby the bordering lowland is drowned on the north and south and the sea is thus allowed to attack the border of the maturely dissected hard-rock uplands along the base of their stripped slope, we should have the best brief explanatory account that I have been able to gather of the north and south coasts of that picturesque region.

During the deduction of a series of imaginary morvans, or during the observation of a number of actual cases, a geographer has occasion to make repeated mention of the essential elements which recur with different values in every example, and he will thus in the most natural manner possible come to designate the elements by the same set of names and to qualify each of them by selected sets of adjectives. He will talk of the undermass or the oldermass, and of the covering strata or overmass or cover, and he will note that in most cases the undermass is composed of disordered resistant crystalline rocks, while the stratified series in the cover are usually less resistant; he will talk of the earlier peneplain, now partly revealed in a stripped belt, where the inclined cover has been worn. off of the undermass; of the later peneplain, now more or less dissected in the upland or highland to which the term morvan more particularly applies, and more or less completely destroyed in the area of the cover, which may indeed be worn down to a third peneplain, and of the morvan angle, namely, the acute angle between the intersecting peneplains. The more definitely these elements are conceived and the more concisely and consistently they are named, the easier will it be to describe new examples, imaginary or real.

\section{THE COLORADO FRONT RANGE IS A MORVAN}

Conceive a morvan in which the undermass was worn down to a remarkably smooth peneplain in its first cycle of erosion, heavily covered with for the most part weak strata, uptilted to the east at a strong angle, then long eroded, so that even the hard rocks of the undermass were reduced to a gently rolling later peneplain, here and there interrupted by good sized monadnocks, irregularly placed, singly or in groups; we should thus have the morvan, which, when again uplifted and this time with broad up-arching to a lofty altitude, and when then submaturely dissected in its harder western undermass, of which the higher parts are well carved by local glaciers, while the weaker eastern covering strata are worn down a thousand feet lower to a new peneplain, would represent the Colorado Front Range and the adjacent plains here under discussion. In other words, the Colorado Front Range is a morvan, in which a belt of the earlier peneplain appears as an inclined surface slanting about 30 
degrees to the east-notched by many revived consequent valleys-along the eastern mountain border, in which the later peneplain is seen in the lofty, gently inclined and maturely dissected highland of the mountainous area, interrupted here and there by strong monadnocks, rising singly or in groups, with strongly glaciated forms in the higher valley heads, and in which the covering strata are as a whole so weak that they are now worn down to a third peneplain of faint relief far and wide to the east of the mountain base, except that a resistant member near the base of the covering strata stands up, parallel to the mountain base, as a subsequent ridge inclosing a piedmont subsequent valley.

It would be interesting again to meet some of the geologists who claimed for geology the account of the Front Range, as given a year ago and here reproduced at the opening of this address, and to ask them whether they would claim for geology also the account of the range just now given as a morvan. The two accounts are unlike in certain respects: the second one is shorter than the first, because the mere introduction of the significant term morvan implies the occurrence of a number of features that had to be explicitly explained in the first account, and the first account contains several verbs in the past tense, while all the verbs in the second account are in the present tense. But in spite of these differences of length and tense, the two accounts are essentially alike, and to my understanding of the case, if the second account belongs to geography, then both the accounts belong there.

\section{CONCEALED GEOLOGICAL MEANING IN VARIOUS GEOGRAPHICAL TERMS}

The most important difference between the two accounts is evidently the lack of the explanatory term morvan in the first and its introduction in the second. The meaning of the term must of course be studied beforehand by any one who wishes easily to understand the second account, and such study manifestly involves a certain familiarity with geology; but this does not warrant the transfẹr of the account from geography to another science. Likewise the meaning of such a term as eleolite-syenite must of course be studied beforehand by any one who hopes to understand a description in which that term is found, and such study manifestly involves a certain knowledge of chemistry and physics; but this does not require the exclusion of such a description from geology.

It is the same with delta, volcano, mature river, and dissected peneplain. Descriptions in which these terms occur can not be understood without previous study of their meaning, and their meaning inevitably involves a consideration of past conditions and processes; nevertheless the terms stand and deserve to remain within the domain of geography. 
The properly explanatory definition of these terms enforces this conclusion. A delta, for example, is not properly defined simply as having a flat lowland surface at a river mouth, nor yet as having been formed by the deposition of river-brought waste at the river mouth, but as having a flat lowland surface, because of having been formed by the deposition of river-brought waste at the river mouth. Similarly a dissected peneplain ought not to be defined as an upland district of subequal altitude, transecting rock structures indifferently and here and there interrupted by valleys, nor yet as a district which once stood lower and was then worn down to low relief by normal erosional processes, and which was afterward uplifted and in this new altitude partly cut down by its revived rivers; but as an upland district, in which the accordant hilltop surface transects the rock structures indifferently because of having been worn down to low relief by normal erosional processes during a former lower stand of the region, and which is now here and there interrupted by valleys because of the revival of erosive processes in virtue of later uplift. Neither the empirical statement of present fact nor the geological account of origin suffices in such definition. A double definition is necessary in which geological,origin is closely associated with present form, for thereby the essentially geographical nature of these terms is made clear.

The same is true of the term morvan. A morvan is not best defined simply as a hard-rock upland, whose resistant mass descends rather smoothly under a neighboring lower district occupied by stratified rocks, nor yet as a region that has been through such and such changes during its long past history, but as a region that exhibits a hard-rock upland or highland bordered by a lower land of slanting stratified rocks because of having suffered such and such changes in its long past history; and thus defined, morvan may be added to the growing list of well established geographical terms.

\section{Part IV. Thy Relation of Geggraphy to Gbology}

\section{GEOGRAPHY IS THE GEOLOGY OF TODAY}

The description of the Colorado Front Range as a morvan will; I trust, be regarded as properly geographical by nearly all members of this Society; but it may still be that some of the more serious objectors may refuse to be blinded by the use of a mere term, and may declare that no such subterfuge can conceal from them the essentially geological quality of any explanatory description that is essentially based on the 
past history of a region. To these members, who very likely think that the word geography has already entered more often than is proper in an address before a geological society, I am prepared to offer still another statement, which it is to be hoped they will find conciliatory, for if they still urge that the account of the Front Range as a morvan belongs under geology I wish now to reply: Of course it does, for all geography belongs under geology, since geography is neither more nor less than the geology of today, and since all geology is essentially the sum of a long succession of past geographies. The separation of the geographical part from the geological whole was a natural consequence of the opinions that prevailed a century ago, when most geographers were merely observational empiricists and most geologists were in large measure fanciful catastrophists; but such a separation is, systematically considered, an absurdity at the beginning of the twentieth century, when we are all convinced that the flow of the past into the present has been without a break, and when we all believe that the geological past, with its days and nights, zones and seasons, calms and storms, lands and waters, rivers and waves, and its striving inhabitants, vegetable and animal, is best pictured in the geographical present, for whatever differences may be found the resemblances are overwhelmingly greater. As the past is indeed nothing but an endless succession of geographies, the present member of the succession naturally claims great attention from geologists as well as from geographers, because it is the visible standard for all the rest; all the earlier members can be known only as departures from it. It is therefore utterly illogical, in so far as the nature of their content is concerned, to classify the past and the present conditions of the earth under two sciences. Consider how closely alike would be the subjects of two investigations, one directed to an account of the earth at the beginning of Carboniferous time, the other to an account of the earth as it is today! Each investigation would treat of a momentary phase in a long evolution; each would introduce as much of the preceding phases as might aid the appreciative understanding of the phase under discussion. To be sure, the study of Carboniferous geography would probably include a considerable discussion of petrographic problems, which would be ordinarily treated lightly in accounts of today's geography, while today's geography would have much to do with local details of mean annual temperatures and rainfalls, which unfortunately can not be minutely treated under Carboniferous geography; hence there would be characteristic differences between the two investigations. Nevertheless the two would have as many elements in common as any two morvans would have, although the elements would of course have different IX-Bull. Geol. Soc. AM., Vol. 23, 1911 
values for Carboniferous time and for today, just as the elements of two morvans, one in France, the other in Colorado, have different values. No; the difference between these two investigations would not lie so much in the unlikeness of their content as in the inherently speculative character and the inevitable incompleteness of one and the largely observational character and the eventually attainable completeness of the other. The speculative character of all conclusions regarding the earth's past history is indeed, when once recognized, so striking that it becomes a matter of surprise to see that geology is largely taught as an observational science, and that direct instruction in the best methods of speculation is ordinarily neglected.

REASONS FOR MAINTAINING EACH AS A SEPARATE SCIENCE

If, then, the content of geology, the long past of the earth, and of geography, the momentary present, are so much alike, why should we make two sciences of them and organize two societies for their cultivation? Chiefly for practical reasons. The degree to which specialization is carried in these modern times demands the division of various subjects that really have a logical unity of content. And among the most important of these practical reasons is that the separation of one group from the whole body of considerations to which the group belongs promotes the concentration of interest and attention on that group, and thus aids its progress. It is only some twenty years ago that geologists and biologists were united in the Society of American Naturalists, and the meetings of that society were so interesting that when it was proposed to segregate the geologists in a society of their own I was one of those who doubted the wisdom of such a step. But the organization of the Geological Society of America has been so beneficial to our science that, far from opposing further subdivision, I took an active part in promoting it when eight years ago a few of us, mostly members of this society, formed the Association of American Geographers; and here again the results gained from independent organization have fully justified the partial isolation that our separation entailed. Our relations are still close, so close indeed that besides a good number of interchangeable members and a somewhat too large number of interchangeable papers, we have in two cases had interchangeable presidents, and as the second one of these I hold it to be a great honor to find myself to that extent in the same category with the first one. 
Nevertheless, the most characteristic papers in the two societies are significantly unlike, and with further development of geographical science I am persuaded that their unlikeness will in certain respects increase, for geographers are going to give more and more attention to the accurate portrayal of existing landscapes-the term landscape being here used in so general a sense that it includes the seas and the skies and their inhabitants along with the lands-while geologists will, I believe, give increas. ing attention to the restoration of ancient landscapes. But the unlikeness will never overcome the likenesses that must maintain the two societies in close relations. Should one of the geographers some day wander, as it is to be hoped he may, into a meeting of the geologists, let us trust that he would have occasion to remark: "That is an excellent account of, for example, the central Appalachian region in Oriskany time, for in spite of being completely speculative, as all restorations of the invisible past must be, it is so ingeniously and logically constructed out of the small existing body of accessible facts, all of which have been patiently searched out and scrupulously used, and it is so successful in vividly portraying the probable conditions and correlations of things, inorganic and organic, throughout central Appalachia in that remote period of earth history which geologists call Oriskany !"

Should, on the other hand, one of the geologists some day visit a meeting of the geographers, where he would surely be welcome, let us hope that he would have good reason for exclaiming: "That is an excellent description of, for example, Patagonia, for while always holding faithfully to the rich store of observable facts, which are sometimes so numerous as to embarrass a geographer from their very abundance, the paper is so significantly suggestive of the evolutionary meaning of the facts, inorganic and organic, and while not for a moment losing sight of the observable present, it so helpfully describes existing conditions in terms of pertinent and illuminating speculations as to their invisible origin, thus showing that the accessible present is really comprehensible only when it is regarded as a continuation of the inaccessible past!"

It is considerations of this nature that make me confident of the abundant work of both these societies and of their sufficient individuality in spite of their close relation; the older one, geology, already well established, penetrating by brilliant speculation the deep structures of the earth's crust and the past conditions, inorganic and organic, of the earth's history, but necessarily basing all its speculations on the facts and conditions of the present surface, which belong so largely in the field of the newer one; the newer one, geography, growing in efficiency year by year, 
124 W. M. DAVIS-RELATION OF GEOGRAPHY TO GEOLOGY

contributing to the wide exploration that in time will cover all the facts and conditions, inorganic and organic, of the earth's present surface, and coming more and more to base its best descriptions on the explanatory speculations regarding structures beneath the earth's surface and regarding the processes and conditions of the earth's past history, that have been so ingeniously invented and so wonderfully well established by studies in the field of the older one. 